\title{
THERMAL PLASMA DECOMPOSITION OF FLUORINATED GREENHOUSE GASES
}

\author{
SOOSEOK CHOI ${ }^{1}$, DONG-WHA PARK ${ }^{2}$, and TAKAYUKI WATANABE ${ }^{1, *}$ \\ ${ }^{1}$ Department of Environmental Chemistry and Engineering, Tokyo Institute of Technology \\ 4259-G1-22, Nagatsuta-cho, Midori-ku, Yokohama 226-8502, Japan \\ ${ }^{2}$ Department of Chemical Engineering and Regional Innovation Center for Environmental \\ Technology of Thermal Plasma (RIC-ETTP), Inha University \\ 253 Yonghyun-dong, Nam-gu, Incheon 402-751, Republic of Korea \\ *Corresponding author. E-mail : watanabe@chemenv.titech.ac.jp
}

Received December 31, 2011

Fluorinated compounds mainly used in the semiconductor industry are potent greenhouse gases. Recently, thermal plasma gas scrubbers have been gradually replacing conventional burn-wet type gas scrubbers which are based on the combustion of fossil fuels because high conversion efficiency and control of byproduct generation are achievable in chemically reactive high temperature thermal plasma. Chemical equilibrium composition at high temperature and numerical analysis on a complex thermal flow in the thermal plasma decomposition system are used to predict the process of thermal decomposition of fluorinated gas. In order to increase economic feasibility of the thermal plasma decomposition process, increase of thermal efficiency of the plasma torch and enhancement of gas mixing between the thermal plasma jet and waste gas are discussed. In addition, noble thermal plasma systems to be applied in the thermal plasma gas treatment are introduced in the present paper.

KEYWORDS : Plasma Torch; Greenhouse Gas; Thermal Decomposition; Destruction and Removal Efficiency (DRE); Chemical Reaction; Flow Field.

\section{INTRODUCTION}

Recently, global warming has been threatening the life of human beings causing climate and ecosystem changes accompanied by various environmental problems. Excessive greenhouse gases in the atmosphere have broken the radiative equilibrium of the earth by absorbing infrared rays radiated from the surface of the earth, and consequently, causing the temperature of the earth to rise. Because of this, international efforts of the Kyoto protocol have been committed to reducing emission of the major greenhouse gases including carbon dioxide $\left(\mathrm{CO}_{2}\right)$, methane $\left(\mathrm{CH}_{4}\right)$, nitrous oxide $\left(\mathrm{N}_{2} \mathrm{O}\right)$, perfluorocarbons (PFCs), hydrofluorocarbons (HFCs), and sulfur hexafluoride $\left(\mathrm{SF}_{6}\right)$. Fluorinated compounds designated as major greenhouse gases by the Kyoto protocol and nitrogen trifluoride $\left(\mathrm{NF}_{3}\right)$ have been widely used in the semiconductor industry, because they are safe and reliable sources of fluorine which is required for etching and cleaning processes for the production of semiconductor devices [1-3]. Although they have seriously high global warming potentials (GWPs) and long atmospheric life time compared with well known greenhouse gas of carbon dioxide as shown in Table 1 [3, 4], significant quantities of fluorinated compounds are emitted due to their low utilization efficiency in the semiconductor manufacturing process [5]. Therefore, World Semiconductor Council (WSC), composed of each semiconductor industry associations in China, Chinese Taipei, Europe, Japan, Korea, and United States, has made an agreement to reduce emissions of fluorinated greenhouse gases in addition to the Kyoto protocol which is restricted to within industrialized countries.

In order to reduce fluorinated compounds emissions from semiconductor manufacturing processes, many different kinds of technologies have been introduced. They include the use of alternative chemicals, process optimizations, recovery of unused gases, and decomposition methods as illustrated in Fig. 1. Alternative chemistry is to determine the use of processing chemicals with low or non-GWP gases substituting for fluorinated gases with high GWP and a long life time [6]. However, currently used stable fluorinated gases have unique chemical properties those make them difficult to be replaced by other materials. In addition, paying attention to unused fluorinated gases, some research has been conducted on capture and recovery techniques such as cryogenic condensation with distillation, pressure swing adsorption, and membrane separation [7]. The semiconductor industry, however, requires the use of highly pure substances to avoid contamination problems. For this reason the capture and recovery technology requires an extensive pretreatment 
Table 1. Global Warming Potential and Atmospheric Life Time of Fluorinated Compounds Generally Used in the Semiconductor Industry Compared to Those of Carbon Dioxide.

\begin{tabular}{c|c|c}
\hline $\begin{array}{c}\text { Fluorinated compound } \\
(\text { Formula })\end{array}$ & $\begin{array}{c}\text { Global warming } \\
\text { potential } \\
{\left[\mathrm{GWP}_{100}{ }^{*}\right]}\end{array}$ & $\begin{array}{c}\text { Atmospheric life } \\
\text { time } \\
{[\text { Year }]}\end{array}$ \\
\hline $\begin{array}{c}\text { Tetrafluoromethane } \\
\left(\mathrm{CF}_{4}\right)\end{array}$ & 6,500 & 50,000 \\
\hline $\begin{array}{c}\text { Hexafluoroethane } \\
\left(\mathrm{C}_{2} \mathrm{~F}_{6}\right)\end{array}$ & 9,200 & 10,000 \\
\hline $\begin{array}{c}\text { Octafluoropropane } \\
\left(\mathrm{C}_{3} \mathrm{~F}_{8}\right)\end{array}$ & 7,000 & 2,600 \\
\hline $\begin{array}{c}\text { Octafluorocyclobutane } \\
\left(\mathrm{C}_{4} \mathrm{~F}_{8}\right)\end{array}$ & 8,700 & 3,200 \\
\hline $\begin{array}{c}\text { Trifluoromethane } \\
\left(\mathrm{CHF}_{3}\right)\end{array}$ & 11,700 & 3,200 \\
\hline $\begin{array}{c}\text { Sulfur hexatluoride } \\
\left(\mathrm{SF}_{6}\right)\end{array}$ & 23,900 & 740 \\
\hline $\begin{array}{c}\text { Nitrogen trifluoride } \\
\left(\mathrm{NF}_{3}\right)\end{array}$ & 11,700 & $50-200$ \\
\hline $\begin{array}{c}\text { Carbon dioxide } \\
\left(\mathrm{CO}_{2}\right)\end{array}$ & 1 & 264 \\
\hline
\end{tabular}

${ }^{*} \mathrm{GWP}_{100}$ : The global warming potential of the gas relative to carbon dioxide for a time interval of 100 years in atmosphere.

system for purification process increasing the cost to that greater than the use of virgin materials. On the other hand, ceaseless efforts have been devoted to optimize the semiconductor manufacturing processes, to minimize the usage of fluorinated compounds as well as to maximize production yield [8]. Nevertheless, additional control methods to reduce fluorinated compound emissions are still required because the semiconductor manufacturing process is exhausting large amounts of fluorinated greenhouse gas even in the optimal condition.

An attempt was made to use low pressure plasmas to decompose unused fluorinated gases effectively in the process chamber of semiconductor manufacturing [9-13] because process gases are diluted with large amounts of nitrogen which is used to purge away particulates from an exhaust pipe $[13,14]$. The foreline treatment, however, causes side effects on the semiconductor manufacturing process due to a back streaming of undesirable materials. Moreover, the vacuum pumps are severely degraded by the corrosive gases produced in the decomposition process. Therefore, an atmospheric pressure treatment after the vacuum pump is favorable for the abatement of fluorinated gases in practical applications. Conventional combustion by using a natural gas burner combined with a wet scrubber [15] is the most well developed and commercialized

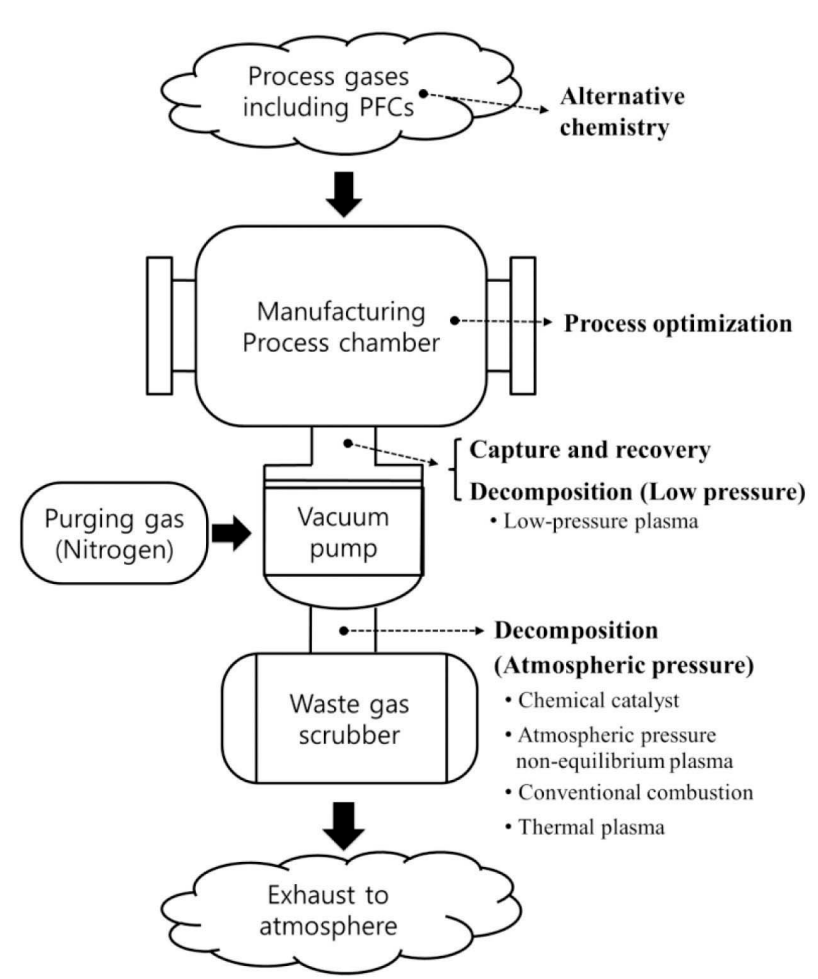

Fig. 1. Reduction Technologies for Fluorinated Compounds Emission from the Semiconductor Manufacturing Process.

method to treat exhaust gas in the semiconductor industry. However, it supplies an insufficient flame temperature to achieve high destruction and removal efficiency (DRE) of $\mathrm{CF}_{4}$ which is the most stable species among fluorinated compounds [16]. Besides the low DRE, the combustion process using fossil fuels has a side effect of generating large quantities of $\mathrm{CO}_{2}, \mathrm{NOx}$, and $\mathrm{SOx}$. In order to overcome these disadvantages in the combustion process, a variety of other methods, such as catalytic conversion [17-19], dielectric barrier discharge [18-21], and microwave discharge at atmospheric pressure [22], have been introduced. These alternative methods using atmospheric pressure non-equilibrium plasmas and chemical catalyst have been reported to destruct fluorinated compounds effectively in low-temperature conditions with high DREs. However, they have shown a limited treatment capacity of less than $1 \mathrm{~L} / \mathrm{min}$ [23], while a typical flow rate of the exhaust gas from a processing chamber for semiconductor manufacturing is several tens $\mathrm{L} / \mathrm{min}$.

Instead of chemical catalyst, atmospheric pressure nonequilibrium plasma, and combustion methods, adoption of the thermal plasma method is gradually increasing to decompose fluorinated compounds in recent years [24-33]. Thermal plasma technology for waste treatment including destruction of fluorinated compounds has received a great 


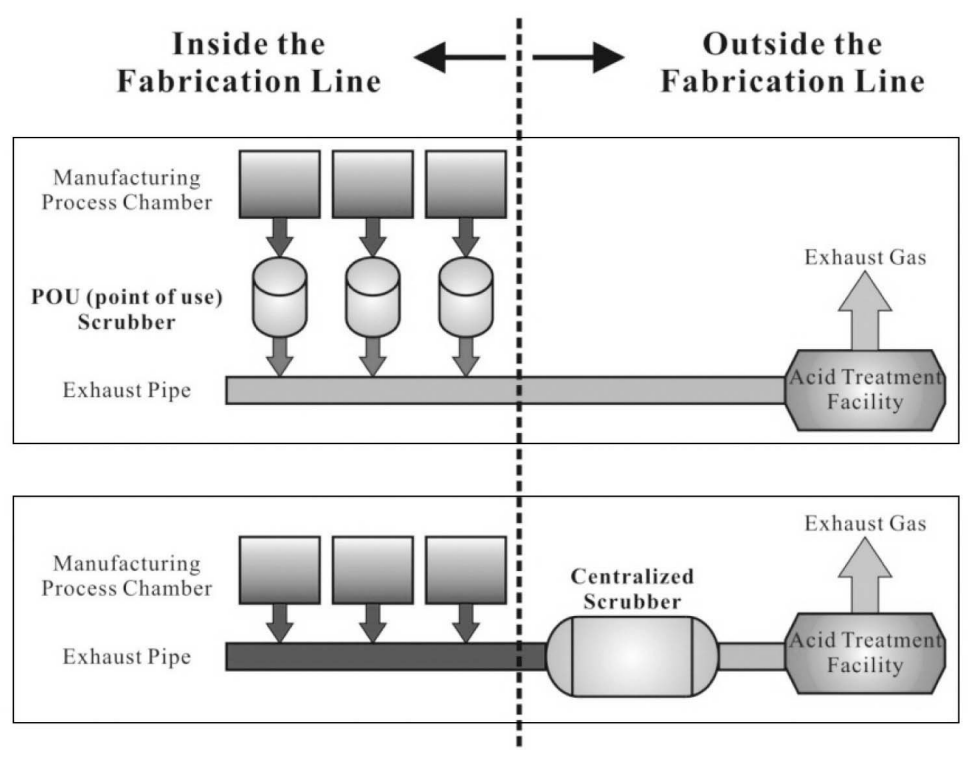

Fig. 2. Schematic Diagram of Gas Treatment Methods at Point of Use (POU) Scrubber and at Centralized Scrubber.

deal of attention to meet the contemporary needs of solving problems with increasing environmental pollution and their restrictions to be followed [34-39]. Thermal plasma has unique advantages such as high heat flux, high temperature, abundant reactive species, fast reaction time, large throughputs in a small reactor, use of clean electric energy, and control over the chemistry. Therefore, chemically reactive high temperature flow of thermal plasma is suitable to decompose non-degradable fluorinated compounds with high DRE controlling byproduct generation. Especially, unwanted oxide byproducts can be strongly suppressed in thermal plasma gas scrubbers when compared with the conventional combustion method, because any kind of gas can be used as a working gas without oxygen in the thermal plasma system. In addition, plasma torches are controllable to increase the power of thermal plasma easily by changing its operating conditions [40]. As a result, it is possible to centralize gas scrubbers that are dispersed in each manufacturing chamber into a large treatment facility as depicted in Fig. 2. Therefore, independent operation and maintenance of waste gas treatment system which is apart from the semiconductor manufacturing line is achievable with high power thermal plasma system.

\section{THERMAL PLASMA GAS SCRUBBER}

The thermal plasma gas scrubber is composed of a plasma torch, decomposition reactor, water scrubbing tower, and aqueous solution chamber as shown in Fig. 3. A high temperature thermal plasma jet is generated from the plasma torch. Waste gas including fluorinated compounds is introduced into the thermal plasma jet in the exterior of the plasma torch to prevent corrosion of electrodes' interior, because fluorinated gases are rapidly decomposed into their constituent elements including corrosive fluorine radicals due to the high temperature of the thermal plasma flame. After the thermal decomposition, the decomposed elements are transformed into stable chemical products with high conversion efficiency when

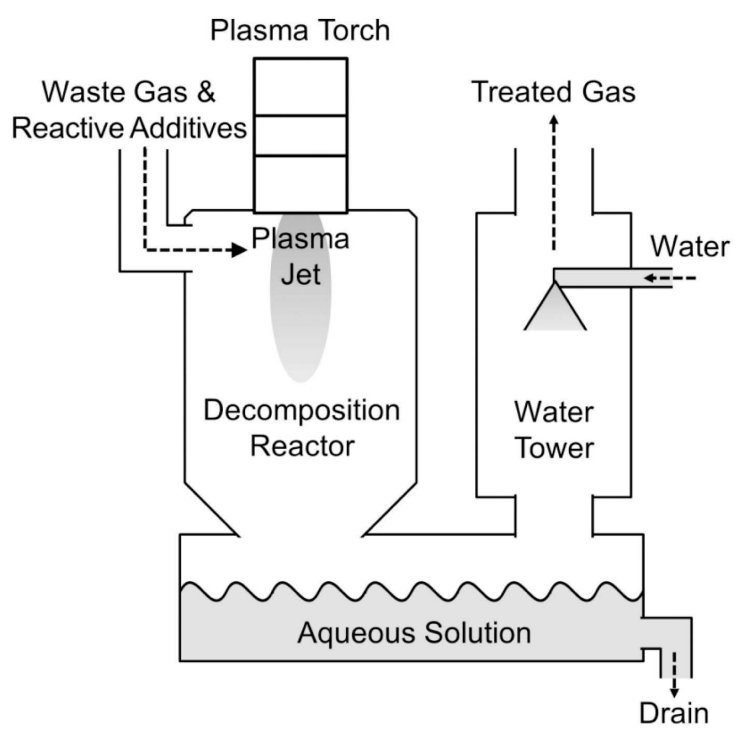

Fig. 3. Schematic Diagram of the Thermal Plasma Gas Scrubber. 
reactants like oxygen and hydrogen are provided. Treated gases pass through the aqueous solution and the water spaying tower where some toxic gases such as HF and $\mathrm{COF}_{2}$ are dissolved, and then remaining environmentally benign gases are emitted into the atmosphere.

Although there are various kinds of plasma torches according to electrode configuration and power source, a rod-nozzle type DC (direct current) plasma torch with an input power of several $\mathrm{kW}$ level has been widely used in practical applications. Nitrogen is supplied as the plasma forming gas, because large quantities of nitrogen have been already used in the semiconductor manufacturing process as a purging gas. For additional reactants, air and steam are commonly used as sources of $\mathrm{H}$ and $\mathrm{O}$ radicals owing to safety issues [30], though it is inevitable that generation of considerable quantities of thermal NOx due to the existence of $\mathrm{O}$ radicals in nitrogen thermal plasma. Moreover, nitrogen is inherently included in waste gas exhausted from the semiconductor manufacturing processes. For this reason, control of NOx generation is still a main problem to be solved in the decomposition processes of fluorinated greenhouse gases emitted from the semiconductor industry, even though the thermal plasma type gas scrubber is used. In order to suppress NOx generation, oxygen should be excluded from the working gas in thermal plasma gas scrubber systems [25]. Therefore, it is required that further studies on the effects of non-oxygen reactive gases such as hydrogen, ammonia, and hydrocarbons on the decomposition of fluorinated compounds to develop more clean treatment processes and to increase conversion efficiency.

Along with the chemical species of working gases used in the thermal decomposition process, it is also important to treat fluorinated compounds effectively such that the characteristics of the thermal flow inside the decomposition reactor where the thermal plasma jet ejected from the torch is mixed with waste gas. Since decomposition of non-degradable fluorinated compounds is directly attributed to the high temperature of the thermal flow, temperature distribution inside the reactor should be considered according to design and operation conditions of the thermal plasma decomposition reactor system. As with temperature, velocity distribution of thermal plasma flame influences residence time for decomposition and conversion of waste gas. In addition, the core region of a thermal plasma jet has an extremely high heat flux distribution, while its peripheral region has too low a temperature to decompose fluorinated compounds due to the steep temperature gradient. Therefore, gas mixing between thermal plasma jet and waste gas is also an important factor to determine the DRE of fluorinated compounds. For these reasons, design and operation variables should be optimized to enhance DRE of fluorinated compounds. Numerical analysis can be used effectively to characterize thermal plasma flow in different conditions, and its results are to understand and improve the decomposition process.

\section{THEORITICAL APPROCHES}

\subsection{Chemical Equilibrium Composition}

Decomposition temperatures of fluorinated compounds and composition of generating byproducts in thermal plasma decomposition processes can be predicted by calculating chemical equilibrium composition [24-26, 28-30, 33, 38]. For the calculation, commercial software for the estimation of chemical reactions and equilibrium composition such as HSC Chemistry (Outokumpu) and FactSage (Center for Research in Computational Thermochemistry) are used. They are linked to thermochemical databases composed of enthalpy $(H)$, entropy $(S)$, and heat capacity $\left(C_{p}\right)$ data for numerous numbers of chemical compounds. The mutual stability of substances can be compared with the Gibbs free energy which can be evaluated from thermochemical data. The equilibrium composition is determined where the Gibbs energy of the multi-component system reaches the minimum value at given mass balance, pressure, and temperature condition by using a numerical method [41]. The equilibrium calculation is typically carried out under constant atmospheric pressure condition, because thermal plasma system is operated in atmospheric pressure. An expected temperature of the mixture between thermal plasma and waste gas in the reactor can be given as temperature range used in the equilibrium calculation.

In Fig. 4, it is shown that the equilibrium composition of waste gas composed of $99 \% \mathrm{~N}_{2}$ and $1 \% \mathrm{CF}_{4}$ which is the most stable and non-degradable species among fluorinated compounds. According to the calculation result, $\mathrm{CF}_{4}$ begins to decompose at $2,000 \mathrm{~K}$ and mostly disappears at 3,000 K. Although, thermal plasma has extremely high temperatures over $10,000 \mathrm{~K}$ in the core region, it has very steep temperature gradient at the same time. Therefore, over $2,000 \mathrm{~K}$ is a high decomposition temperature to achieve sufficiently high DRE of $\mathrm{CF}_{4}$. As a result, reactive additives are required to decrease decomposition temperature. The decomposition temperature

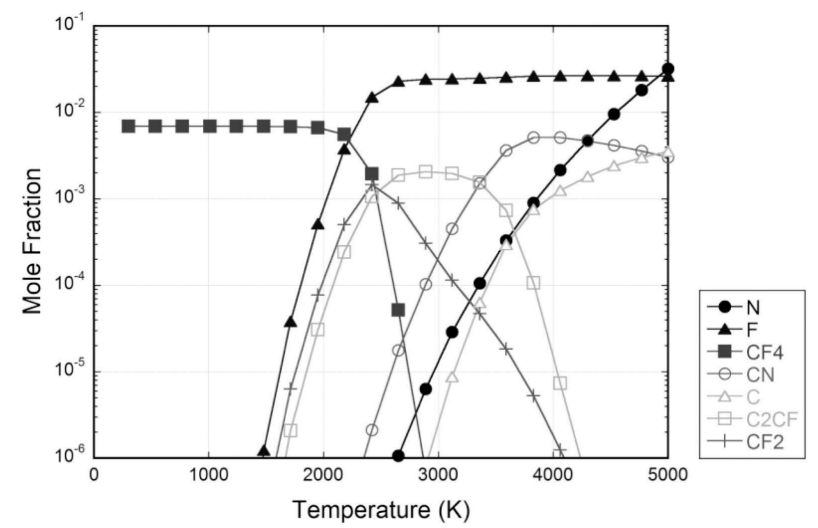

Fig. 4. Equilibrium Compositions of Waste Gas Composed of $99 \% \mathrm{~N}_{2}$ and $1 \% \mathrm{CF}_{4}$ According to Temperature. 
of $\mathrm{CF}_{4}$ can be decreased to $1,710 \mathrm{~K}$ with the help of hydrogen, because Gibbs free energy of the follow reaction changed to negative from that temperature [25].

$$
\mathrm{CF}_{4}+2 \mathrm{H}_{2} \rightarrow \mathrm{C}(\mathrm{s})+4 \mathrm{HF}
$$

Although carbon deposits are expected in the above decomposition reaction, the exhaust pipe of the gas scrubber should be cleaned periodically due to particulates that come from the semiconductor manufacturing process.

The effect of water addition on thermal decomposition of HFC-134a is presented in Fig. 5 [29]. Large amounts of fluorinated byproducts such as $\mathrm{CF}_{4}, \mathrm{CF}_{3}, \mathrm{CF}_{2}, \mathrm{CF}$, and $\mathrm{F}$ are generated by elevating the temperature without water as shown in Fig. 5 (a). Therefore, thermal decomposition of HFC-134a can produce more the serious greenhouse gas of $\mathrm{CF}_{4}$ during cooling down process unless an appropriate reactive additive is not provided. On the contrary, formation of $\mathrm{CF}_{4}$ can be strongly suppressed by adding water as predicted in Fig. 5 (b). Because HFC-134a is converted into $\mathrm{CO}_{2}$ and $\mathrm{CO}$ by $\mathrm{O}$ radicals and it is also converted into $\mathrm{HF}$ and $\mathrm{CH}_{4}$ by $\mathrm{H}$ radicals, simultaneously. Although water
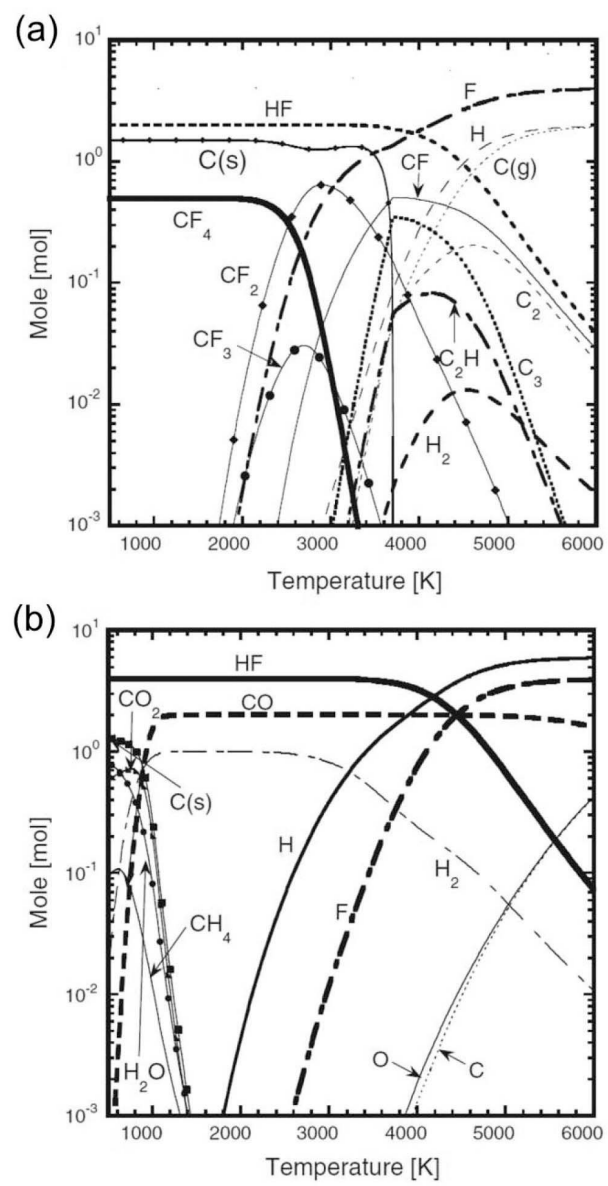

Fig. 5. Equilibrium Compositions of (a) HFC-134a and (b) Mixture of HFC-134a and Water [29]. is unfavorable to prevent generation of NOx in nitrogen atmosphere of the exhaust gas from the semiconductor industry, it can be effectively employed to decompose HFCs which are used as refrigerants in various applications such as refrigerators, air conditioners, and cars [42-45].

As shown in this section, fluorinated compounds' decomposition in different temperatures generates various kinds of byproducts according to the working gas condition. Therefore, the prediction of the decomposition temperature and byproducts species based on chemical equilibrium calculations is the first step to design a thermal plasma gas decomposition system which uses the suitable working gas for each of the target waste gases.

\subsection{Numerical Analysis on Thermal Plasma Flow}

Numerical analyses on thermal plasma jets and mixture flows of plasma with the waste gases are required to examine the effects of operation and design conditions of thermal plasma systems on the decomposition process of fluorinated compounds. From the numerical simulation, it is obtained that the major factors of the thermal decomposition process such as distributions of temperature, velocity, and each species in the decomposition reactor [26, 32, 33]. The numerical simulation is divided into two steps according to the existence or absence of the arc column inside the computational domain as shown in Fig. 6. First, the arc

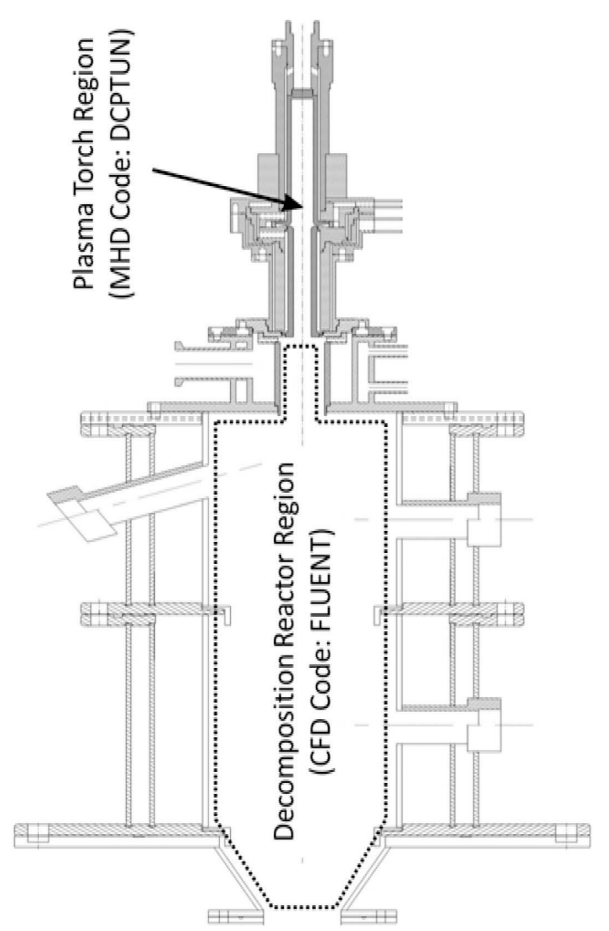

Fig. 6. Computational Domains and Numerical Codes Used for the Thermal Plasma Modeling in the Interior Regions of the Plasma Torch and the Decomposition Reactor. 
plasma characteristics in the arc discharge region of the torch interior are numerically analyzed by using a MHD (magnetohydrodynamics) code which has been developed to simulated thermal plasmas [46-50]. Second, the thermal plasma characteristics inside the decomposition reactor region where a complex thermal flow mixture between plasmas jet and waste gas is formed, can be precisely and stably simulated by using a commercial CFD (computational fluid dynamics) code, FLUENT (ANSYS), which has been widely used for solving complex hydrodynamic flows.

In the numerical simulation, the governing fluid equations consisting of mass, momentum, and energy conservation are solved under the steady-state, twodimensional, and axis-symmetric conditions. Although the turbulent thermal plasma is an inherently threedimensional time transient phenomena, a time averaged axis-symmetric modeling on thermal plasma jets have been in good agreement with experimentally measured results [50-52]. Since the $k-\varepsilon$ turbulence model is widely used for turbulent thermal plasma flow modeling, it is also incorporated to include turbulence effects [53]. In the torch region, the radiative energy transfer is considered by the assumption of optically thin plasma with the net emission coefficient in the state of local thermodynamic equilibrium (LTE) [54]. In the torch interior region, electromagnetic properties such as current density and magnetic fields are important to simulate plasma discharge phenomena because Lorentz force and Joule heating should be included in momentum and energy conservations, respectively. Therefore, distribution of the arc current density and the self-induced magnetic fields are obtained from the current continuity equation along with the generalized Ohm's law and Ampere's law. Each simulation on torch and reactor regions are coupled by using temperature and velocity profiles at the torch exit calculated from the first step as the reactor inlet boundary conditions in the second step. In the simulations, precalculated data on high temperature thermodynamic and transport properties of working gases and components included in the computational domain [55-57] are linked with each simulation code.

As an example of numerical analysis, temperature distributions inside the reaction chamber for HFC-23 decomposition are presented in Fig. 7 [32]. In this work, a thermal plasma jet was generated from a rod-nozzle type DC plasma torch. The waste gas of HFC-23 was injected into the thermal plasma flame in a radial direction after flowing along a channel formed between the reactor wall and the outer reaction tube. Steam was used to enhance the decomposition reaction and to control byproducts, and it was also injected into the plasma flame after preheating through a channel between the outer and inner reaction tubes. As shown in Fig. 7 (a), higher arc current produces a higher temperature distribution inside the reactor region. Decomposition temperature of HFC-23 is reported as $1,437 \mathrm{~K}$ [58], and a sufficiently high temperature of over $1,500 \mathrm{~K}$ is seen in the majority of the inside of the inner reaction tube with the arc current of $50 \mathrm{~A}$. In addition to temperature distribution, residence time of waste gas in the high temperature plasma flame was also evaluated as $50 \mathrm{~ms}$ in the case of $50 \mathrm{~A}$ based on the length of the reactor and numerical result on velocity distribution. Effects of reactor geometry on temperature profile of the inner reaction tube which is exposed to high heat flux of the thermal plasma flame was also examined with the numerical analysis illustrated in Fig. 7 (b) because a melting problem of the inner reaction tube frequently arose in the experiment. The melting point of reaction tubes made of Inconel metal is known to be $1,600 \sim 1,700 \mathrm{~K}$, and it was required from the numerical results that along gap distance between the reactor inlet and the outer reaction tube was required to prevent melting of the inner reaction tube. By taking advantage of the results of numerical analysis, high DRE of HFC-23 was achieved without thermal damage of the reactor in the thermal plasma decomposition system [32].

(a)
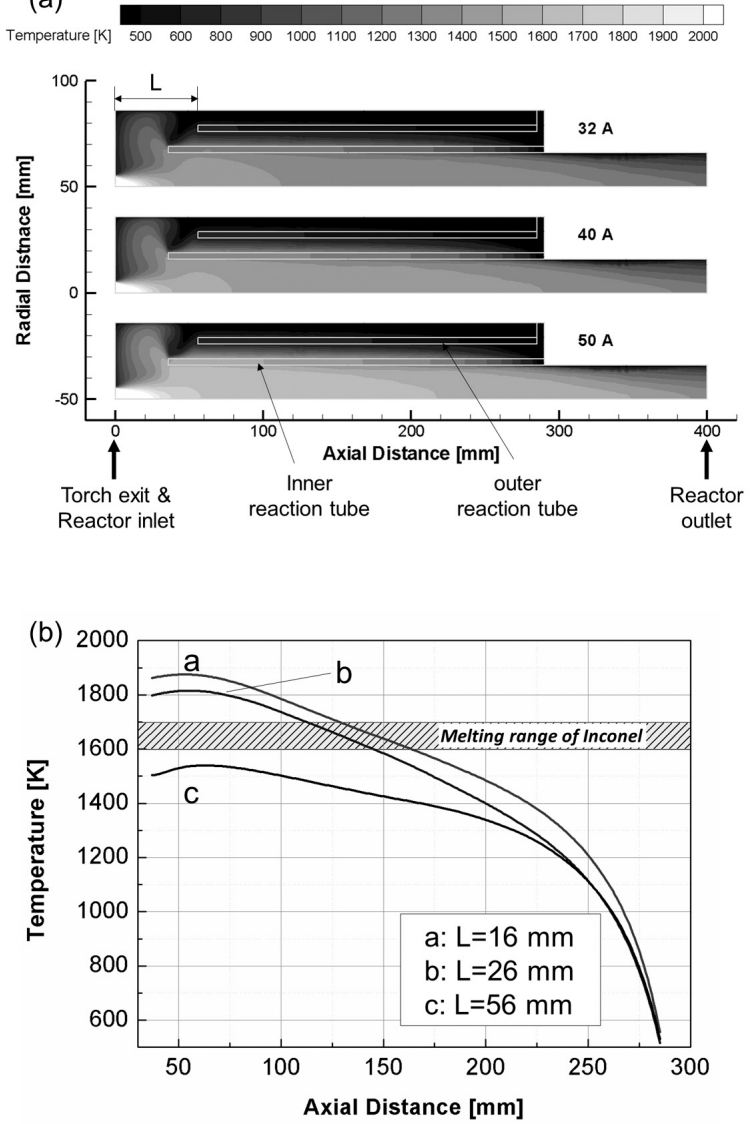

Fig. 7. Numerical Simulation Results on the Reactor Region in Thermal Plasma Decomposition of HFC-23: (a) Effects of Arc Current in Plasma Torch on Temperature Distribution Inside the Reactor; (b) Effects of Reactor Geometry on Temperature Profile of the Inner Reaction Tube Exposed to High Heat Flux of Thermal Plasma Flame [32]. 
Numerical analysis is essentially required to understand complex thermal flow and to find out optimal operation and design conditions in the thermal plasma gas decomposition system because development of thermal plasma system based on a trial and error method dissipates much time and cost. In numerical analysis on the thermal plasma gas decomposition system, the decomposition temperature predicted from the chemical equilibrium composition can be compared with temperature distribution inside the reactor to find a high DRE condition within various design and operation variables. Moreover, useful information for the decomposition process such as residence time and proper configuration of the reactor are also obtainable from the numerical analysis.

\section{IMPROVEMNET OF THE DECOMPOSITION PROCESS}

Recently, thermal plasma gas decomposition systems have begun to replace conventional combustion systems in practical applications such as the treatment of exhaust gas from semiconductor manufacturing processes and elimination of used refrigerants. The main cause of the demand on thermal plasma technology is high temperature which cannot be accomplished in the combustion method. However, thermal plasma provides not only high temperature but also the controllability on the process of fluorinated compounds decomposition compared with the combustion method. Although, achievement of high DRE of nondegradable fluorinated compounds became possible by changing the combustion burner into the plasma torch, there is still room for improvement of the decomposition process. Some recent research on improvement of the decomposition process based on the unique benefits from the use of thermal plasma technology is discussed in the present chapter.

\subsection{Effects of Operation and Design Variables of the Plasma Torch}

The typical thermal plasma system requires a plasma torch, plasma forming gas supply, power supply to sustain electric input power, and coolant to protect each component of the plasma torch from the high heat flux of the thermal plasma. The plasma torch has a thermal efficiency which is defined as the fraction of input power transferred to the thermal plasma jet ejected from the torch depending on the operation condition. Since waste gas is introduced into the thermal plasma jet in the exterior of the torch, heat loss into the torch coolant should be decreased to increase the economic feasibility of thermal plasma application for the fluorinated gas decomposition process by achieving a high net power of the thermal plasma jet with a relatively low electric input power.

Basically, thermal efficiency of the plasma torch is strongly affected by torch operating conditions. The operation variables of discharge current and gas flow rate have an effect on the dynamic behavior of the arc discharge which determines torch performance and thermal plasma characteristics in the plasma torches [59-60]. In the thermal decomposition of $200 \mathrm{~L} / \mathrm{min}$ waste gas including $\mathrm{CF}_{4}$ with a hollow electrode plasma torch [26], experimental results of time average arc voltage $(V)$, electric input power $\left(P_{i n}\right)$, thermal efficiency of the torch $(\eta)$, net plasma thermal power $\left(P_{n e t}\right)$, and destruction and removal efficiency of $\mathrm{CF}_{4}$ $(D R E)$, are listed in Table 2 according to torch operation variables of discharge current $(I)$ and plasma gas flow rate $(Q)$. Although input powers were varied from 39.6 to $59.9 \mathrm{~kW}$, high $\mathrm{CF}_{4}$ DREs of over $96.9 \%$ were resultant in all operating conditions due to sufficiently high net powers of the plasma flame over $20 \mathrm{~kW}$. It is because that the highest thermal efficiency was achieved in torch operation with the lowest input power at high arc current of $130 \mathrm{~A}$ and low plasma gas flow rate of $70 \mathrm{~L} / \mathrm{min}$. In order to unearth the reason of the high thermal efficiency of the

Table 2. Arc Current (I), Flow Rate of Plasma Forming Gas $(Q)$, Resultant Arc Voltage ( $\boldsymbol{V}$, Input Power $\left(P_{\text {in }}\right)$, Thermal Efficiency $(\boldsymbol{\eta})$, Net Thermal Power $\left(P_{\text {net }}\right)$, and DRE of $\mathrm{CF}_{4}$ (DRE) in Large Scale Thermal Decomposition of $\mathrm{CF}_{4}$ with Hollow Electrode Plasma Torch [26].

\begin{tabular}{|c|c|c|c|c|c|c|}
\hline $\begin{array}{c}\boldsymbol{I} \\
(\mathrm{A})\end{array}$ & $\underset{(\mathrm{L} / \mathrm{min})}{\boldsymbol{Q}}$ & $\begin{array}{c}\boldsymbol{V} \\
(\mathrm{V})\end{array}$ & $\begin{array}{c}P_{\text {in }} \\
(\mathrm{kW})\end{array}$ & $\underset{(\%)}{\boldsymbol{\eta}}$ & $\begin{array}{c}\boldsymbol{P}_{\text {net }} \\
(\mathrm{kW})\end{array}$ & $\begin{array}{c}\text { DRE } \\
(\%)\end{array}$ \\
\hline 130 & 70 & 397.4 & 51.7 & 42.7 & 22.1 & 97.4 \\
\hline 130 & 90 & 392.9 & 51.1 & 43.3 & 22.1 & 99.5 \\
\hline 140 & 70 & \multicolumn{3}{|c|}{ Unstable arc discharge } & - & - \\
\hline 140 & 90 & 406.3 & 56.9 & 40.4 & 23.0 & 98.5 \\
\hline 150 & 70 & 264.3 & 39.6 & 51.8 & 20.6 & 96.9 \\
\hline 150 & 90 & 398.1 & 59.7 & 41.8 & 25.0 & 99.4 \\
\hline
\end{tabular}




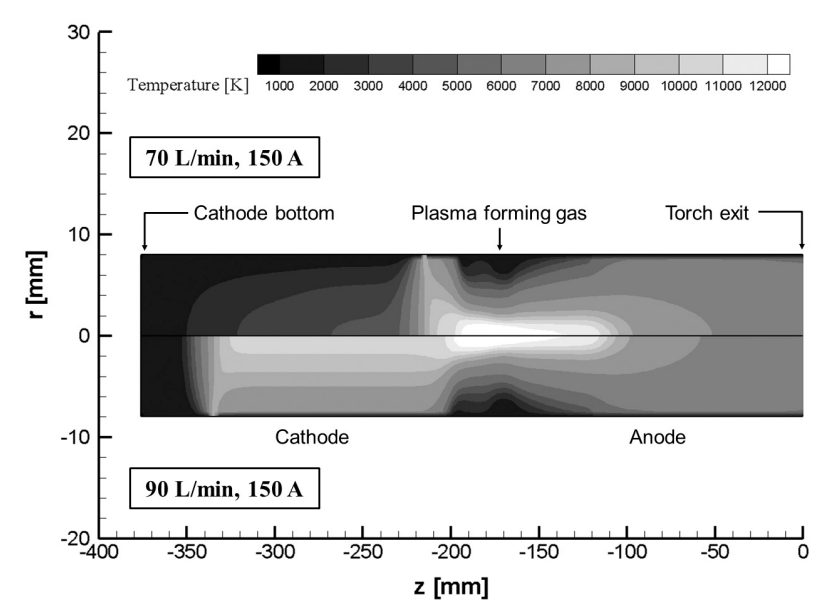

Fig. 8. Comparison of Plasma Temperature Distributions Inside the Torch Operated in Different Plasma Gas Flow Rates of 70 and $90 \mathrm{~L} / \mathrm{min}$, Respectively.

plasma torch, numerical analysis was carried out as shown in Fig. 8. Temperature distributions inside the torch are compared for different plasma gas flow rates of 70 and $90 \mathrm{~L} / \mathrm{min}$ at the same input current of $150 \mathrm{~A}$. Since the large flow rate of cold plasma forming gas disturbs a stable cathodic arc attachment near the gas injection position, a cathodic arc spot is placed near the bottom of the cathode. As a result, a large area of high temperature is distributed at the higher flow rate condition with an enlarged arc length. Therefore, the heat loss from the high temperature thermal plasma into the cathode coolant is increased in the torch operation with high gas flow rate, while the highest thermal efficiency is achieved in the case of low plasma gas flow rate due to a short arc length. For different arc current conditions at the same low gas flow rate of $70 \mathrm{~L} / \mathrm{min}$, low arc current of $130 \mathrm{~A}$ was not effective to forma short arc length due to relatively low temperature and electric conductivity distributions near the plasma gas injection area.

Together with the thermal efficiency of the torch, the steep temperature gradient of the thermal plasma jet is also one of the main reasons for low utilization of electric input power in the thermal plasma decomposition process. Therefore, enhancement of gas mixing between cold waste gas and high temperature plasma jet is required for an efficient decomposition of non-degradable fluorinated compounds. The intrinsic turbulent nature of thermal plasma enhances the mixing process between the plasma jet and waste gas through the entrainment process [51, 61, 62]. Turbulent intensities are compared in Fig. 9 according to different gas flow rates. Although the case of low plasma gas flow rate showed high thermal efficiency of the plasma torch as discussed above [26], it has relatively weak turbulent flow and low DRE compared with those in the high plasma gas flow rate case. Therefore, in order to resolve this trade-off between thermal efficiency of the

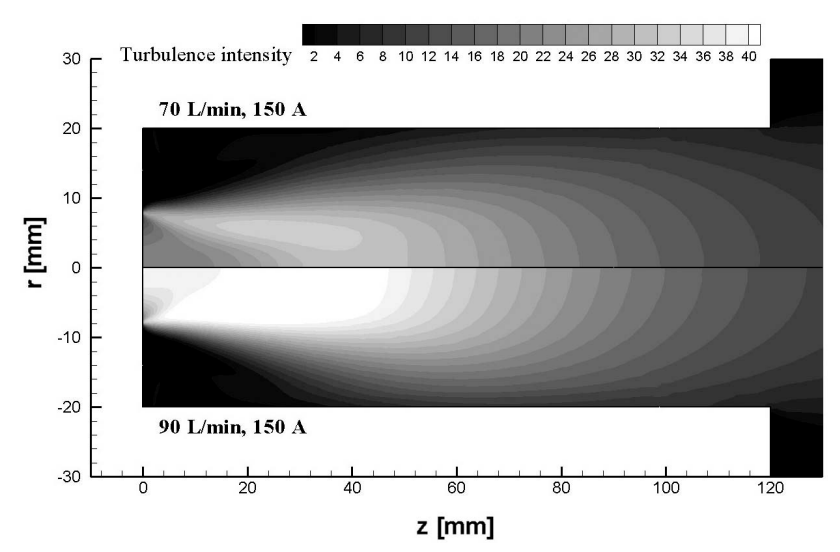

Fig. 9. Comparison of Turbulence Intensity Distributions Inside the Decomposition Reactor at Different Plasma Forming Gas Flow Rates.

plasma torch and DRE of fluorinated compound, an improvement of the decomposition process by enhancing gas mixing between thermal plasma and waste gas is needed. As a way of enhancing the turbulent gas mixing between the plasma jet and waste gas, it was suggested that the rotation of thermal flow in the decomposition reactor by swirling the thermal plasma jet. For the purpose of the swirl motion of thermal plasma jet, a permanent magnet was inserted around the anode region of the plasma torch as schematically drawn in Fig. 10. Externally applied magnetic fields $\left(B_{z}\right)$ interact with arc discharge currents $\left(j_{r}\right)$ generating azimuthal Lorentz forces $\left(F_{\theta}\right)$ on the anodic arc root. Different from the torch operation without permanent magnets, the thermal plasma jet has a swirl motion driven by the anodic arc root rotation in the torch operation with permanent magnet as seen in Fig. 11. The generation of numerous large eddies and the radial expansion of high temperature region of thermal plasma jet are appeared as results of the rotating arc motion. In

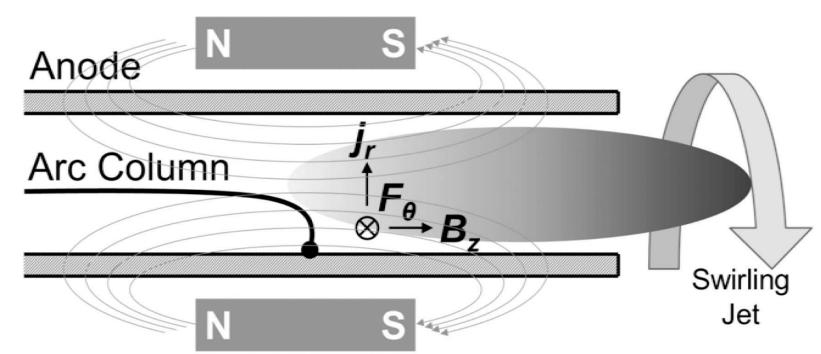

Fig. 10. Schematic Diagram of Rotating Anodic Arc Root and Resultant Swirling Plasma Jet Driven by Azimuthal Lorentz Force. 


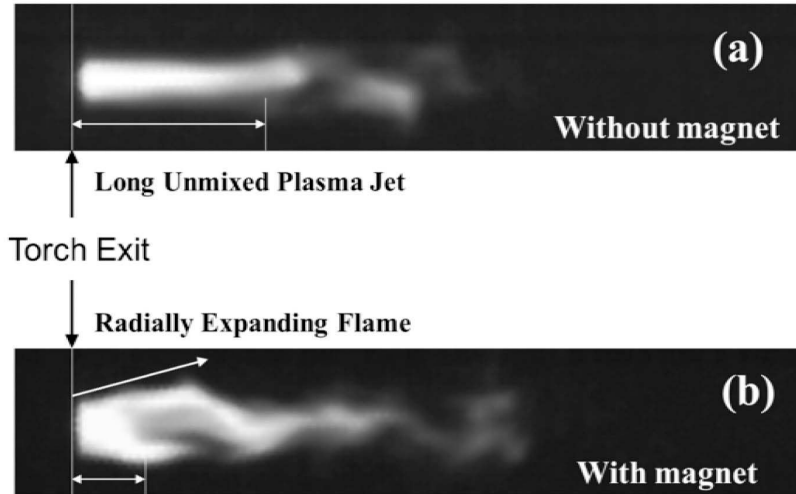

Short Unmixed Plasma Jet

Fig. 11. Snapshot of the Thermal Plasma Flame Ejected from a Hollow Electrodes Plasma Torch (a) in the Absence and (b) in the Presence of Permanent Magnets.

the experiment on $\mathrm{CF}_{4}$ decomposition at fixed operating conditions of $70 \mathrm{~L} / \mathrm{min}$ and $150 \mathrm{~A}$ for plasma torch and $400 \mathrm{~L} / \mathrm{min}$ for waste gas, an increased DRE by $20 \%$ was achieved with enhanced gas mixing driven by an external magnetic field [31]. This method of permanent magnet insertion on the anode part of a plasma torch is very useful for the practical non-degradable gas decomposition process, because it is simple and does not require additional maintenance cost.

\subsection{Noble Plasma Torches for Decomposition of Fluorinated Compounds}

Development of noble plasma generators is being researched to improve thermal plasma waste treatment in addition to the optimization of operation and design variables in typical plasma torches. Among of them, the water plasma torch [27-29, 38, 63-65] and the long dc arc plasma torch $[66,67]$ are promising thermal plasma technologies to decompose fluorinated compounds effectively.

The water plasma torch and the water plasma system to decompose fluorinated gases are drawn in Fig. 12. In the water plasma torch, the arc channel is formed between a hafnium embedded rod type cathode and nozzle type anode and plasma supporting gas is steam which is directly evaporated from the water reservoir due to a strong heat flux of thermal plasma. Hafnium inserted in the cathode prevents the erosion keeping durability in oxidative atmosphere. Since the evaporated steam is cooling down the anode nozzle, additional cooling systems which are essential in typical plasma torches is not needed. As a result, a high thermal efficiency of $86 \%$ is achievable in the water plasma torch [38]. A large part of the evaporated water is converted into $\mathrm{H}, \mathrm{O}$, and $\mathrm{OH}$ radicals during thermal plasma generation and such abundant radicals

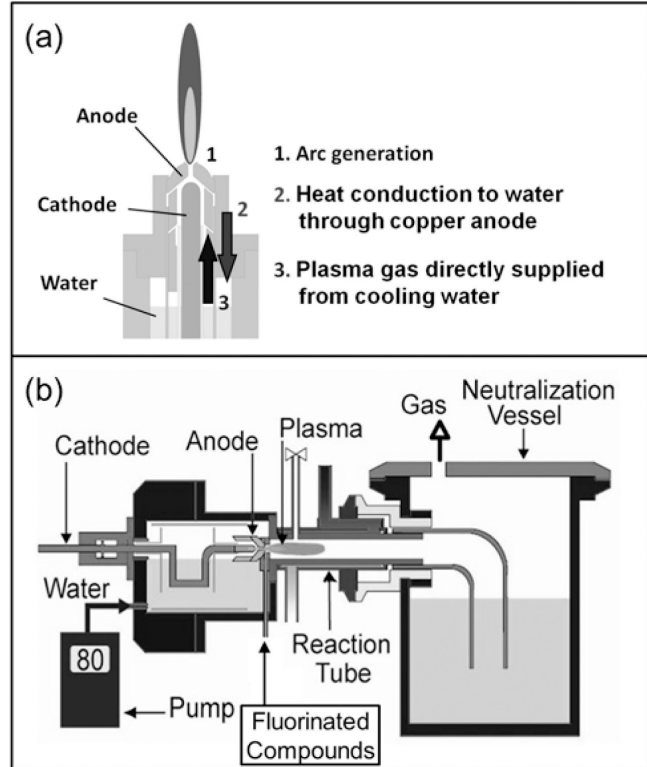

Fig. 12. Schematic Diagrams of (a) Water Plasma Torch and (b) Water Plasma System for the Decomposition of Fluorinated Compounds.

promote chemical reactions of the decomposition of fluorinated compounds in the high temperature of thermal plasma flame. Therefore, the water plasma system converts fluorinated compounds into environmentally benign and stable materials effectively with a high thermal efficiency of the torch and abundant radicals in the plasma flame. Furthermore, the water plasma torch has an advantage of direct use of a liquid waste as plasma supporting material instead of pure water [63-65]. For these reasons, the compact and energy efficient water plasma system can be effectively applied to treat a variety of waste including fluorinated compounds.

The long DC arc discharge plasma torch is suitable to produce large volume thermal plasma compared with that generated from the conventional DC plasma torches such as the rod-nozzle type plasma torch and hollow electrode plasma torch. In this noble plasma torch, cathode and anode are placed at the top and the bottom of the system, respectively. Saline solution or auxiliary metal wire is used to make the breakdown in the long electrode gap distance of several tens of $\mathrm{mm}$. An arc channel connected between the two electrodes and thermal plasma flow are confined by the surrounding tube. Therefore, the plasma volume is controllable by changing electrode gap distance and diameter of the confinement tube in the long DC arc system. In Fig. 13, thermal plasma volume is compared between the conventional hollow electrode plasma torch and the noble long DC arc discharge plasma torch. Although significantly low input power was supplied to the long DC arc discharge, it produced a relatively large 
Hollow electrode plasma torch

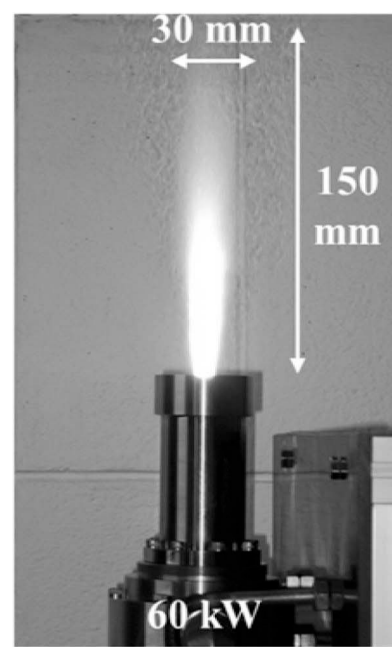

Long DC are plasma torch

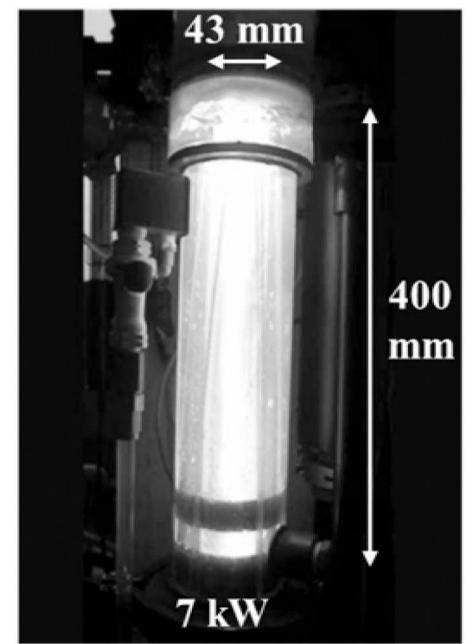

Fig. 13. Comparison of Thermal Plasma Volume Generated from the Conventional Hollow Electrode Plasma Torch and the Noble Long DC Arc Discharge Plasma Torch.

volume of thermal plasma which provides long residence time of waste gas in the high temperature region of thermal plasma. In addition, fluorinated compounds included in waste gas can be directly used as plasma forming gas, while it is introduced into the thermal plasma flame in the exterior of the plasma torch in the currently used thermal plasma gas scrubber. Therefore, the long DC arc discharge plasma torch is a favorable thermal plasma system to decompose non-degradable fluorinated compounds due to a large volume of high temperature thermal plasma with a low input power.

\section{CONCLUSION}

The conventional combustion method is being substituted by thermal plasma technology in order to decompose fluorinated compounds effectively. Thermal plasma processes provide enhanced chemical reaction dynamics with the availability of any kinds of working gas as well as sufficiently high temperature. Therefore, high DRE of non-degradable greenhouse gas is achievable with suppression of unwanted byproduct generation. Although several researches have been devoted to improve the thermal plasma decomposition process for fluorinated compounds, thermal plasma still has potentials for advancement. For more clean and economical thermal plasma decomposition of fluorinated compounds, it is required that studies on reactive additives for different waste gas, optimization of torch design and operation, and development of new thermal plasma torch fit for the decomposition process.

\section{ACKNOWLEDGMENTS}

This work was supported by the Regional Innovation Center for Environmental Technology of Thermal Plasma (ETTP) at Inha University designated by Ministry of Knowledge and Economy of Republic of Korea (2011).

\section{REFERENCES}

[1] C. C. Allgood, "Fluorinated Gases for Semiconductor Manufacture: Process Advances in Chemical Vapor Deposition Chamber Cleaning”, J. Fluorine Chem., vol. 122, pp. 105-112 (2003).

[2 ] J. P. Chang and J. W. Coburn, "Plasma-Surface Interactions", J. Vac. Sci. Tech. A, vol. 21, pp. S145-S151 (2003).

[3] J. V. Gompel, "PFCs in the Semiconductor Industry: A Primer", Semicon. Int., vol. 23, pp. 321-330 (2000).

[4] R. Ravishankara, S. Solomon, A. A. Turnipseed, and R. F. Warren, "Atmospheric Lifetimes of Long-Lived Halogenated Species”, Science, vol. 259, pp. 194-199 (1993).

[ 5 ] I. Namose, "Optimization of Gas Utilization in Plasma Processes”, IEEE Tran. Semicon. Manufacturing, vol. 16, pp. 429-435 (2003).

[6] S. Samukawa and T. Mukai, "New Radical Control Method for High-Performance Dielectric Etching with Nonperfluorocompound Gas Chemistries in UltrahighFrequency Plasma", J. Vac. Sci. Tech. A, vol. 17, pp. 25512556 (1999).

[7] W. -T. Tsai, H. -P. Chen, and W. -Y. Hsien, "A Review of Uses, Environmental Hazards and Recovery/Recycle Technologies of Perfluorocarbons (PFCs) Emissions from the Semiconductor Manufacturing processes", J. Loss Prevention Proc. Ind., vol. 15, pp. 65-75 (2002).

[ 8 ] T. Streif, G. DePinto, S. Dunnigan, and A. Atherton, "PFC Reduction through Process and Hardware Optimization", Semicon. Int., vol. 20, pp. 129-134 (1997). 
[9] V. Mohindra, H. Chae, H. H. Sawin, and M. T. Mocella, "Abatement of Perfluorocompounds (PFCs) in a Microwave Tubular Reactor Using $\mathrm{O}_{2}$ as an Additive Gas", IEEE Trans. Semicond. Manuf., vol. 10, pp. 399-411 (1997).

[10] B. A. Wofford, M. W. Jackson, C. Hartz, and J. W. Bevan, "Surface-Wave Plasma Abatement of $\mathrm{CHF}_{3}$ and $\mathrm{CF}_{4}$ Containing Semiconductor Process Emissions", Environ. Sci. Tech., vol. 33, pp. 1892-1897 (1999).

[11] X. P. Xu, S. Rauf, and M. J. Kushner, "Plasma Abatement of Perfluorocompounds in Inductively Coupled Plasma Reactors", J. Vac. Sci. Tech. A, vol. 18, pp. 213-231 (2000).

[12] T. Kuroki, J. Mine, S. Odahara, M. Okubo, T. Yamamoto, and N. Saeki, "CF ${ }_{4}$ Decomposition of Flue Gas From Semiconductor Process Using Inductively Coupled Plasma”, IEEE Trans. Ind. Appl., vol. 41, pp. 221-228 (2005).

[13] E. J. Tonnis, V. Vartanian, L. Beu, T. Lii, R. Jewett, and David Graves, "Evaluation of a Litmas "Blue" Point-of-Use (POU) Plasma Abatement Device for Perfluorocompound (PFC) Destruction", Technology Transfer \#98123605AENG, International SEMATECH (1998).

[14] J. P. Fournier and M. E. Elta, "Utilizing a Portable Cycle Purge Nitrogen Venturi for Removal of Process Gases in Semiconductor Processing gas Systems", J. Vac. Sci. Tech. A, vol. 10, pp. 3376-3377 (1992).

[15] J. V. Gompel and T. Walling, "A New Way to Treat Process Exhaust to Remove CF4", Semicon. Int., vol. 20, pp. 95-100 (1997).

[16] D. R. Burgess, Jr., M. R. Zachariah, W. Tsang, and P. R. Westmoreland, "Thermochemical and Chemical Kinetic Data for Fluorinated Hydrocarbons", Prog. Energy Combust. Sci., vol. 21, pp. 453-529 (1996).

[17] G. M. Bickle, T. Suzuki, and Y. Mitarai, "Catalytic Destruction of Chlorofluorocarbons and Toxic Chlorinated Hydrocarbons", Appl. Catal. B: Environ., vol. 4, pp. 141153 (1994).

[18] S. Futamura and A. Gurusamy, "Synergy of Nonthermal Plasma and Catalysts in the Decomposition of Fluorinated Hydrocarbons", J. Electrostatics, vol. 63, pp. 949-954 (2005).

[19] S. J. Yu and M. B. Jang, "Oxidative Conversion of PFC via Plasma Processing with Dielectric Barrier Discharges", Plasma Chem. Plasma Process., vol. 21, pp. 311-327 (2001).

[20] K. Urashima, K. G. Kostov, J. -S. Chang, Y. Okayasu, T. Iwaizumi, K. Yoshimura, and T. Kato, "Removal of $\mathrm{C}_{2} \mathrm{~F}_{6}$ from a Semiconductor Process Flue Gas by a Ferroelectric Packed-Bed Barrier Discharge Reactor with an Adsorber", IEEE Tran. Ind. Appl., vol. 37, pp. 1456-1463 (2001).

[21] Y. Kim, K. T. Kim, M. S. Cha, Y. H. Song, and S. J. Kim, " $\mathrm{CF}_{4}$ Decompositions Using Streamer- and Glow-Mode in Dielectric Barrier Discharges", IEEE Trans. Plasma Sci., vol. 33, pp. 1041-1046 (2005).

[22] Y. C. Hong and H. S. Uhm, "Abatement of $\mathrm{CF}_{4}$ by Atmospheric-Pressure Microwave Plasma Torch", Phys. Plasma, vol. 10, pp. 3410-3414 (2003).

[23] M. B. Chang and J. -S. Chang, "Abatement of PFCs from Semiconductor Manufacturing Processes by Nonthermal Plasma Technologies: A Critical Review", Ind. Eng. Chem. Res., vol. 45, pp. 4101-4109 (2006).

[24] J. W. Sun and D. W. Park, " $\mathrm{CF}_{4}$ Decomposition by Thermal Plasma Processing”, Korean J. Chem. Eng., vol. 30, pp. 476-481 (2003).

[25] S. Choi, H. S. Lee, C. M. Lee, J. S. Nam, and S. H. Hong,
"Comparative Study between Air and Nitrogen Thermal Plasma Process for $\mathrm{CF}_{4}$ Decomposition", Proc. 18th Int. Symp. Plasma Chem. (ISPC18), Kyoto, Japan, Aug. 26-31, 2007.

[26] S. Choi, H. S. Lee, S. Kim, S. H. Hong, and D. -W. Park, "Thermal Plasma Analysis for the Pyrolysis of PFCs on a Large Scale", J. Korean Phys. Soc., vol. 55, pp. 1819-1824 (2009).

[27] D. -y. Kim and D. W. Park, "Decomposition of PFCs by Steam Plasma at Atmospheric Pressure", Surface Coat. Tech., vol. 202, pp. 5280-5283 (2008).

[28] Narengerile, H. Saito, and T. Watanabe, "Decomposition of Tetrafluoromethane by Water Plasma Generated under Atmospheric Pressure", Thin Solid Films, vol. 518, pp. 929-935 (2009).

[29] Narengerile, H. Saito, and T. Watanabe, "Decomposition Mechanism of Fluorinated Compounds in Water Plasmas Generated under Atmospheric Pressure", Plasma Chem. Plasma Process., vol. 30, pp. 813-829 (2010).

[30] S. -H. Han, H. -W. Park, T. -H. Kim, and D. -W. Park, "Large Scale Treatment of Perfluorocompounds Using a Thermal Plasma Scrubber", Clean Tech., vol. 17, pp. 250-258 (2011).

[31] S. Choi, S. H. Hong, D. -W. Park, and T. Watanabe, "Thermal Plasma Technology for Non-Degradable Greenhouse Gases Treatment", Proc. The 24th Symp. Plasma Sci. Mater. (SPSM-24), Osaka, Japan, Jul. 19-20, 2011.

[32] S. Choi, K. Y. Cho, J. M. Woo, J. C. Lim, J. K. Lee, "Numerical Analysis on a Thermal Plasma Reactor for HFC-23 Treatment", Current Appl. Phys., vol. 11, pp. S94-S98 (2011).

[33] T. -H. Kim, S. Choi, and D. -W. Park, "Numerical Simulation on the Influence of Water Spray in Thermal Plasma Treatment of $\mathrm{CF}_{4}$ gas", Current Appl. Phys., vol. 12, pp. 509-514 (2012).

[34] R. Benocci, G. Bonizzoni, and E. Sindoni, "Thermal Plasmas for Hazardous Waste Treatment”, World Scientific (1995).

[35] P. Fauchais and A. Vardelle, "Thermal Plasmas", IEEE Tran. Plasma Sci., vol. 25, pp. 1258-1280 (1997).

[36] E. Pfender, "Thermal Plasma Technology: Where Do We Stand and Where Are We Going?", Plasma Chem. Plasma Proc., vol. 19, pp. 1-31 (1999).

[37] S. -W. Kim, H. -S. Park, and H. -J. Kim, "100 kW Steam Plasma Process for Treatment of PCBs (Polychlorinated Biphenyls) Waste", Vacuum, vol. 70, pp. 59-66 (2003).

[38] T. Watanabe, "Water Plasma Generation under Atmospheric Pressure for Waste Treatment", ASEAN J. Chem. Eng., vol. 5, pp. 30-34 (2005).

[39] J. Heberlein, and A. B. Murphy, "Thermal plasma waste treatment”, J. Phys. D: Appl. Phys., vol. 41, 053001 (2008).

[40] S. H. Hong, et al., "Optimal Design and Fabrication Technology of Thermal Plasma Torches for Industrial Application", Seoul National University (2005).

[41] W. B. White, S. M. Johnson, G. B. Dantzig, "Chemical Equilibrium in Complex Mixtures", J. Chem. Phys., vol. 28, pp. 751-755 (1958).

[42] E. Johnson, "Global Warming from HFC", Environ. Impact Assess. Rev., vol. 18, pp. 485-492 (1998).

[43] G. Angelinoa and C. Invernizzib, "Experimental Investigation on the Thermal Stability of Some New Zero ODP Refrigerants", Int. J. Refrig., vol. 26, pp. 51-58 (2003).

[44] A. McCullocha and A. A. Lindley, "Global Emissions of 
HFC-23 Estimated to Year 2015”, Atmos. Environ., vol. 41, pp. 1560-1566 (2007).

[45] M. Mohanraj, S. Jayaraj, and C. Muraleedharan, "Environment Friendly Alternatives to Halogenated Refrigerants-A review", Int. J. Greenhouse Gas Control, vol. 3, pp. 108119 (2009).

[46] K. D. Kang and S. H. Hong, "Arc Plasma Jets of a Nontransferred Plasma Torch", IEEE Trans. Plasma Sci., vol. 24, pp. 89-90 (1996).

[47] M. Hur and S. H. Hong, "Comparative Analysis of Turbulent Effects on Thermal Plasma Characteristics inside the Plasma Torches with Rod- and Well-Type Cathodes", J. Phys. D: Appl. Phys., vol. 35, pp. 1946-1954 (2002).

[48] J. M. Park, K. S. Kim, T. H. Hwang, and S. H. Hong, "Three-Dimensional Modeling of Arc Root Rotation by External Magnetic Field in Nontransferred Thermal Plasma Torches", IEEE Tran. Plasma Sci., vol. 32, pp. 479-487 (2004).

[49] S. Choi, J. M. Park, W. T. Ju, and S. H. Hong, "Effects of Constrictor Geometry, Arc Current, and Gas Flow Rate on Thermal Plasma Characteristics in a Segmented Arc Heater", J. Therm. Sci. Tech., vol. 6, pp. 210-218 (2011).

[50] K. S. Kim, J. M. Park, S. Choi, J. Kim, and S. H. Hong, "Comparative Study of Two- and Three-Dimensional Modeling on Arc Discharge Phenomena inside a Thermal Plasma Torch with Hollow Electrodes", Phys. Plasma, vol. 15, 023501 (2008).

[51] S. Choi, T. H. Hwang, J. H. Seo, D. U. Kim, and S. H. Hong, "Effects of Anode Nozzle Geometry on Ambient Air Entrainment Into Thermal Plasma Jets Generated by Nontransferred Plasma Torch, IEEE Trans. Plasma Sci., vol. 32, pp. 473-478 (2004).

[52] K. S. Kim, J. M. Park, S. Choi, J. Kim, and S. H. Hong, "Enthalpy Probe Measurements and Three-Dimensional Modelling on Air Plasma Jets Generated by a NonTransferred Plasma Torch with Hollow Electrodes", $J$. Phys. D: Appl. Phys., vol. 41, 065201 (2008).

[53] B. E. Launder and D. B. Spalding, "The Numerical Computation of Turbulent Flows", Comp. Method. Appl. Mech. Eng., vol. 31, pp. 269-289(1974).

[54] A. Gleizes, J. J. Gonzalez, and P. Freton, “Thermal Plasma Modeling”, J. Phys. D: Appl. Phys., vol. 38, pp. R153-R183 (2005).

[55] A. B. Murphy, and C. J. Arundell, "Transport Coefficients of Argon, Nitrogen, Oxygen, Argon-Nitrogen, and ArgonOxygen Plasmas", Plasma Chem. Plasma Process., vol. 14 pp. 451-490 (1994).

[56] A. B. Murphy, "Transport Coefficients of Air, Argon-Air, Nitrogen-Air, and Oxygen-Air Plasmas", Plasma Chem. Plasma Process., vol. 15, pp. 279-307 (1995).

[57] I. Sokolova, "High Temperature Gas and Plasma Transport Properties of $\mathrm{F}_{2}$ and $\mathrm{CF}_{4}$ Mixtures", Fluid Phase Equilib., vol. 174, pp. 213-220 (2000).

[58] W. Han, E. M. Kennedy, S. K. Kundu, J. C. Mackie, A. A. Adesina, and B. Z. Dlugogorski, "Experimental and Chemical Kinetic Study of the Pyrolysis of Trifluoroethane and the Reaction of Trifluoromethane with Methane", $J$. Fluor. Chem., vol. 131, pp. 751-760 (2010).

[59] J. -F. Brilhac, B. Pateyron, J. -F. Coudert, P. Fauchais, and A. Bouvier, "Study of the Dynamic and Static Behavior of dc Vortex Plasma Torch: Part II: Well-Type Cathode", Plasma Chem. Plasma Proc., vol. 15, pp. 257-277 (1995).

[60] J. F. Coudert, M. P. Planche, and P. Fauchais, "Characterization of D. C. Plasma Torch Voltage Fluctuations”, Plasma Chem. Plasma Proc., vol. 16, pp. 211S-227S (1996).

[61] E. Pfender, "Plasma Jet Behavior and Modeling Associated with the Plasma Spray Process", Thin Solid Films, vol. 238, pp. 228-241 (1994).

[62] J. R. Fincke, D. M. Crawford, S. C. Snyder, W. D. Swank, D. C. Haggard, and R. L. Williamson, "Entrainment in High-Velocity, High-Temperature Plasma Jets. Part 1: Experimental Results", Int. J. Heat Mass Transfer, vol. 46, pp. 4201-4213 (2003).

[63] M. -H. Yuan, Narengerile, T. Watanabe, and C. -Y. Chang, "DC Water Plasma at Atmospheric Pressure for the Treatment of Aqueous Phenol", Environ. Sci. Tech., vol. 44, pp. 47104715 (2010).

[64] Narengerile, H. Nishioka, and T. Watanabe, "Mechanisms of Decomposition of Organic Compoundsby Water Plasmas at Atmospheric Pressure", Jpn. J. Appl. Phys., vol. 50, 08JF13 (2011).

[65] Narengerile, and T. Watanabe, "Acetone Decompositionby Water PlasmasatAtmospheric Pressure", Chem. Eng. Sci., vol. 69, pp. 296-303 (2012).

[66] T. Li, S. Choi, T. Watanabe, T. Nakayama, and T. Tanaka, "Discharge and Optical Characteristics of Long DC Arc Plasma", Proc. The 24th Symp. Plasma Sci. Mater. (SPSM24), Osaka, Japan, Jul. 19-20, 2011.

[67] S. Choi, T. Li, T. Watanabe, T. Nakayama, and K. Otsuki, "Thermal Plasma Characterization on Long DC Arc Discharge for Waste Treatment", Proc. Plasma Conf. 2011 (Plasma 2011), Kanazawa, Japan, Nov. 22-25, 2011. 